\title{
Applications of an Updated Atmospheric Energetics Formulation
}

\author{
KeVIn E. TrenBerth ${ }^{\mathrm{a}}$ AND JOHn T. FASUllo \\ National Center for Atmospheric Research, Boulder, Colorado
}

(Manuscript received 8 December 2017, in final form 24 April 2018)

\begin{abstract}
As observations and atmospheric reanalyses have improved, the diagnostics that can be computed with confidence also increase. Accordingly, a new formulation of the energetics of the atmosphere is laid out, with a view to advancing diagnostic studies of Earth's energy budget and flows. It is utilized to produce assessments of the vertically integrated divergences in both the atmosphere and ocean. Careful conservation of mass is required, with special attention given to the hydrological cycle and redistribution of mass associated with precipitation and evaporation, and a new method for ensuring this is developed. It guarantees that the atmospheric divergence is associated with moisture and precipitation, unlike previous methods. A new term, identified as associated with the enthalpy of precipitation, is included in a preliminary way. It is sensitive to the formulation, and the use of temperature in degrees Celsius instead of Kelvin greatly reduces errors and produces the extra term with values up to about $\pm 5 \mathrm{~W} \mathrm{~m}^{-2}$. New results for 2000 to 2016 are presented for the vertical-mean and annual-mean diabatic atmospheric heating, atmospheric moistening, and total atmospheric energy divergence. Results for the atmospheric divergence are combined with top-of-atmosphere radiation observations to deduce total surface energy fluxes. Along with estimates of changes in ocean heat content, the Atlantic Ocean meridional heat transports are recomputed for March 2000 through 2013. The new results are compared with previous estimates and an assessment is made of the effects of the new mass balance, change in temperature scale, and the extra precipitation enthalpy term.
\end{abstract}

\section{Introduction}

Climate change is becoming increasingly evident in all analyses of the climate system and especially in the atmosphere, ocean, cryosphere, and land surface. The changes arise mainly from the increasing human influence on climate through the changes in composition of the atmosphere, principally by increasing carbon dioxide and other greenhouse gases (IPCC 2013). Carbon dioxide has increased from about $280 \mathrm{ppm}$ by volume to over $400 \mathrm{ppm}$, a $43 \%$ increase, and over half of that increase has occurred since 1980. The increased heat-trapping gases change the energy balance of the planet, and tracking the energy imbalance and anomalous flows in space and time has become an imperative for better understanding the way climate change is manifested (von Schuckmann et al. 2016).

The energy imbalance clearly varies quite substantially over time (Trenberth et al. 2014, 2016). Many short-term fluctuations associated with weather and

\footnotetext{
a ORCID: 0000-0002-1445-1000.
}

Corresponding author: Kevin E. Trenberth, trenbert@ucar.edu variations in cloud, and thus albedo, occur but tend to be self-correcting (Trenberth et al. 2015a,b), as a deficit in one month changes the weather to produce a surplus in the next. Interannual variations associated with El Niño-Southern Oscillation (ENSO) are substantial, and typically are order $\pm 0.5 \mathrm{~W} \mathrm{~m}^{-2}$. They are associated with fluctuations in global-mean surface temperature (GMST; Trenberth et al. 2002a, 2014; Mayer et al. 2014), as heat is stored in the oceans before being redistributed and released back into the atmosphere with an El Niño event. Larger perturbations of order $2 \mathrm{~W} \mathrm{~m}^{-2}$ occur for annual-mean energy imbalances associated with major volcanic eruptions (e.g., Trenberth et al. 2014), but last only a few years. In the longer term, the energy imbalance associated with human-induced climate change results in increases in ocean heat content (OHC), which have been well measured since 2005 when Argo reached global implementation (Cheng et al. 2017). Since then the $\mathrm{OHC}$ has increased by $0.8 \pm 0.2 \mathrm{~W} \mathrm{~m}^{-2}$ (Trenberth et al. 2016). Unfortunately, many $\mathrm{OHC}$ analyses are characterized by very large spurious fluctuations associated with intermittent observations (Trenberth et al. 2016). A new analysis of the OHC back to 1960 (Cheng et al. 2017) nicely documents its global and regional 
changes. They show that the main increases are small prior to about 1980, and only since about 1990 has the OHC increased substantially below about 700-m depth. However, the increases are greatest in the southern oceans, and tropical/subtropical Atlantic. Accordingly, the influences via sea surface temperature (SST) on the atmosphere result in regional changes in climate.

To better understand past climate variations as well as provide a basis for future predictions, it is essential to track the variations in top-of-atmosphere (TOA) radiation, the atmospheric movement and storage of energy, and the exchanges with the surface that are then manifested as changes in OHC over the oceans, or changes in moisture and heat over land (Trenberth and Fasullo 2013). Our approach to assessing energy flows through the climate system has been to fully utilize the TOA radiation along with vertically integrated atmospheric transports of energy to deduce the surface energy fluxes as a residual (Trenberth 1991; Trenberth and Solomon 1994; Trenberth 1997; Trenberth et al. 2001; Trenberth and Caron 2001; Trenberth and Stepaniak 2003a,b; Fasullo and Trenberth 2008a,b; Trenberth and Fasullo 2008, 2010, 2013). Mayer and Haimberger (2012) have adopted a similar framework. Trenberth and Fasullo (2017) were able to combine the estimated surface fluxes with $\mathrm{OHC}$ changes to deduce time series of vertically integrated ocean heat transport throughout the Atlantic that could be verified by direct ocean observations at $26.5^{\circ} \mathrm{N}$.

In these diagnostic studies, a number of approximations were made, including assumptions about certain terms and numerical approximations. It was found to be essential to first balance the atmospheric mass budget in order to get reasonable results (Trenberth 1991, 1997; Trenberth et al. 1995). Most studies, including Mayer and Haimberger (2012) and Mayer et al. (2017), focus on the vertically integrated atmosphere and utilized a simplified mass budget correction based on a barotropic adjustment to the mass field. Earlier atmospheric reanalyses were mainly available on pressure surfaces and had limited vertical resolution. The synoptic nature of rawinsondes (once or twice daily) meant that there were spurious diurnal variations and the semidiurnal tide was poorly depicted (Trenberth 1991). The mass budget was seriously violated, especially in the tropics. Barotropic divergent velocity corrections of order $0.3 \mathrm{~m} \mathrm{~s}^{-1}$ were required at very large scales. Full use of computations on native model coordinates greatly improved the results, but largescale corrections were still essential, evidently because analysis increments upset balances (Trenberth 1997).

The formulation of the atmospheric energy and mass budgets included certain approximations. Even today, most models do not properly deal with the mass budget and instead assume conservation of atmospheric mass that fails to properly account for precipitation. Trenberth (1991) recognized the redistribution of mass associated with evaporation $E$ and precipitation $P$ and included it in their computations. However, this was not done consistently from an energy standpoint, as noted by Mayer et al. (2017). In addition, only water vapor was included, not liquid or ice phases of moisture, and the gas constants for latent heat and specific heat were treated as constants. Models, including those used for atmospheric reanalysis, generally include these aspects nowadays, but it is difficult to include them in diagnostic calculations that deal with time averages, owing to nonlinearities. Some of these terms are indeed small, but some are not, and the purpose of this paper is to reformulate the mass and energy budgets of the atmosphere to make them more consistent.

We continue to work in a somewhat simplified formulation that utilizes hydrostatic approximations. The original atmospheric reanalyses are in hybrid coordinates and these are utilized for vertical integrals to eliminate approximations from that source. However, we formulate the equations to work in pressure coordinates. Pressure reflects atmospheric mass and accordingly it varies with the amount of moisture in the atmosphere. Newer model formulations that are nonhydrostatic may use dry atmospheric pressure as a coordinate, as it has the advantage of being conserved and appears to provide a better way to fully account for vapor, liquid, and ice water in the atmosphere.

The full set of equations dealing with water in all of its phases is very complicated. Makarieva et al. (2017) recently derived a corrected set of the equations of motion for moist air, updated from Ooyama (2001) and Bannon (2002). Emanuel (1994) has a useful textbook describing moist thermodynamic processes and the governing equations. The thermodynamic equations are also given in texts such as Cotton et al. (2011), along with conventional approximations. They discuss the shortcomings of using a reversible thermodynamics formulation when condensate is present and falls out as precipitation, and the alternative approach of adopting pseudoadiabatic thermodynamics whereby the condensate is immediately removed. They discuss the many approximations related to neglect of viscous effects, turbulent mixing, ice phase, sedimentation terms such as differential fall velocities of hydrometeors, hydrometeor-air interaction, heat conduction, and dissipative heating. Often in modeling clouds, conservation of quantities is not essential, but for climate and long-term averages, conservation of energy and mass is essential.

The improved mass budget and energetic equations are developed in section 2, along with the newly revised mass correction procedures. Section 3 discusses the new extra term that arises and relates to the precipitation enthalpy. 
Section 4 provides a new set of results and compares them with the previous method, and section 5 discusses the results in the context of another attempt to advance the diagnostic procedures. Mayer et al. (2017) have attempted to deal with some of the shortcomings noted here but have introduced other assumptions that have questionable validity, which are discussed in section 5.

\section{Budget equations}

The dry atmosphere is considered to be a mixed gas with a single gas constant that follows the ideal gas laws, and this works well until one gets to the stratosphere, where ozone plays a role, and especially above about $80-\mathrm{km}$ altitude where the ionosphere begins. However, it is essential to properly consider water substance separately. As a first approximation one can consider only water vapor, but because precipitation is a vital part of the climate system, liquid water and ice particles also need to be considered. These are nevertheless considered well mixed in a volume so that they all have the same temperature and the volumes of liquid and ice water are negligible.

The partial pressures of the dry and vapor gaseous components are

$$
\begin{aligned}
p_{d} & =\left(1-q_{v}-q_{l}-q_{i}\right) \rho R T, \\
p_{v} & =q_{v} \rho R_{v} T, \text { and } \\
p & =\rho R_{m} T,
\end{aligned}
$$

where $q$ is the specific humidity with components and subscripts for $v$ vapor, $l$ liquid, and $i$ ice, and $R$ is the gas constant for dry air $R_{d}$, water vapor $R_{v}$, or moist air $R_{m}$, with

$$
R_{m}=\left(1-q_{v}-q_{l}-q_{i}\right) R_{d}+q_{v} R_{v} .
$$

The specific heat at constant volume is given by $c_{\mathrm{vm}}=$ $\left(1-q_{v}-q_{l}-q_{i}\right) c_{\mathrm{vd}}+q_{v} c_{\mathrm{pv}}+q_{l} c_{\mathrm{vl}}+q_{i} c_{\mathrm{vi}}$, and the specific heat at constant pressure is $c_{\mathrm{pm}}=c_{\mathrm{vm}}+R_{m}$. Note there is some lack of parallel between $c_{v}$ and $c_{p}$ owing to the fact that liquid and ice phases are not gases (and thus do not contribute to $R$ ). For our purposes these differences are very small and negligible.

\section{a. Mass}

We use the hydrostatic primitive equations in pressure coordinates, although these may face difficulties in properly dealing with water substance. The full equation of continuity in pressure coordinates is

$$
\nabla \cdot \mathbf{v}+\frac{\partial \omega}{\partial p}=e-c
$$

where $\mathbf{v}$ is the horizontal velocity; $\omega$ is the vertical $p$-velocity; and $e$ and $c$ are the evaporation and condensation rates. The latter arise from the conservation of moisture equation in flux form, which is

$$
\frac{\partial q}{\partial t}+\nabla \cdot q \mathbf{v}+\frac{\partial q \omega}{\partial p}=e-c,
$$

and $q=q_{v}$ is the specific humidity for vapor, and is conserved in the absence of sources and sinks, ignoring the liquid and ice contributions. The right-hand side (rhs) is equal to $-\partial q_{l} / \partial t$, the change in liquid water, and is related to the net precipitation. In (5) the mass of dry air is constant.

The mass-weighted vertical integral of any quantity $M$ integrated in the vertical over the mass of the atmosphere from the bottom $\left(p=p_{s}, z=0\right)$ to the top ( $p=$ $\left.p_{t}=0, z=\infty\right)$, where, for practical reasons, it may often be necessary to recognize some other value than zero for $p_{t}$, is given by

$$
\tilde{M}=\int_{0}^{\infty} \rho M d z=\frac{1}{g} \int_{p_{t}}^{p_{s}} M d p=\frac{1}{g} \int_{\eta_{s}}^{\eta_{t}} M \frac{\partial p}{\partial \eta} d \eta,
$$

and the latter is in hybrid $\eta$ model coordinates, where $\eta_{t}$ corresponds to $p=p_{t}=0$ and $\eta_{s}$ corresponds to $p=p_{s}$.

The total mass of the atmosphere $m$ in a column is $\tilde{m}=m_{d}+w=p_{s} / g$, where $m_{d}$ is the mass of dry air, and the water vapor contribution as precipitable water $w=1 / g \int_{0}^{p_{s}} q_{v} d p$. Desirably, we should also include a liquid $q_{l}$ and ice $q_{i}$ phase of water as well, but these amounts are usually very small. It is necessary to acknowledge them in the context of precipitation, which is an irreversible process that removes mass from the atmosphere, while mass may be replaced where evaporation occurs.

The mass of dry air is conserved, so that

$$
\frac{\partial m_{d}}{\partial t}+\nabla \cdot \frac{1}{g} \int_{0}^{p_{s}}(1-q) \mathbf{v} d p=0,
$$

while for water vapor

$$
\frac{\partial w}{\partial t}+\nabla \cdot \frac{1}{g} \int_{0}^{p_{s}} q \mathbf{v} d p=E-P .
$$

Combining these gives

$$
\frac{1}{g} \frac{\partial p_{s}}{\partial t}+\nabla \cdot \frac{1}{g} \int_{0}^{p_{s}} \mathbf{v} d p=E-P,
$$

and we have ignored other forms of liquid and frozen water in the atmosphere, but these can be included in a similar manner. These are consistent with (5) and (6). 
Note that for a steady state (or ignoring the tendency terms),

$$
\nabla \cdot \int_{0}^{p_{s}} \mathbf{v} d p=\nabla \cdot \int_{0}^{p_{s}} q \mathbf{v} d p
$$

The above avoids the details of the precipitation process. Rather, moisture convergence results in condensation with amount $d q_{l}=-d q_{v}$, which will give rise to latent heat release $L d q_{l}$, and this is taken as a reversible process in which enthalpy is conserved. However, if this liquid condensate $d q_{l}$ is precipitated out, then the process is no longer reversible, and entropy increases. We then should consider the enthalpy associated with the exchanged mass.

Businger (1982) notes that specific enthalpies should be formulated with extra terms involving constants, so that sensible heat $\mathrm{SH}=c_{p} T+b$ reflects the energies present in the substances. Hence, the constants, $b$, differ for vapor versus liquid versus solid water forms, and the problems arise when we are dealing with an open system requiring "careful bookkeeping." Businger (1982) discusses the merits of using a reference temperature of $0^{\circ} \mathrm{C}$ rather than $0 \mathrm{~K}$. In the latter case, an extra term related to the sensible heat of liquid (and solid) water is necessary. Oceanographers formulate their equations in degrees Celsius, which is natural, as it is the value for transition to ice.

In the following, we reference the sensible heat to a temperature $T_{0}$, which may well be $0^{\circ} \mathrm{C}$, or it might be the triple point of water; then the enthalpy of the precipitation is $c_{l} d q_{l}\left(T-T_{0}\right)$, where $T$ is the temperature of the air at that location. If it is cold enough, the ice phase and the latent heat of fusion is also involved. The drops of precipitation may be warmed as they fall and they may evaporate some moisture back into the air, and it is not obvious what the temperature of the precipitation drops $T_{p}$ will be when they hit the ground. If the precipitation rate is $P$, then the enthalpy associated with precipitation is $c_{l} P\left(T_{p}-T_{0}\right)$, and this process transfers the enthalpy out of the atmosphere (Businger 1982) to the surface, where the temperature is $T_{s}$, and where $c_{l}$, the specific heat of water is $4186 \mathrm{~J} \mathrm{~kg}^{-1} \mathrm{~K}^{-1}$, and $T_{0}$ is $0^{\circ} \mathrm{C}$, while $T_{p}$ is the temperature of the precipitation. For $P$ of $5 \mathrm{~mm} \mathrm{day}^{-1}$, this is of order $1 \mathrm{~W} \mathrm{~m}^{-2}$. At the surface, where the difference is $c_{l} P\left(T_{p}-T_{s}\right)$, an assumed value for $T_{p}$ is often the wet bulb temperature, with some justification (Gosnell et al. 1995). The latter compute an average cooling value of $2.5 \mathrm{~W} \mathrm{~m}^{-2}$ for the tropical Pacific warm pool region.

\section{b. Energy}

Energy in the atmosphere consists of kinetic energy $k$, internal energy $I=c_{v} T$, and potential energy $P_{e}$ (e.g., see Trenberth 1997). It is readily shown that $E=I+k+$ $P_{e}$, when integrated over the entire mass of the atmosphere, is conserved in the absence of heating and friction.

The vertically integrated $P_{e}$ is given by

$$
\widetilde{P_{e}}=\int_{0}^{\infty} g z \rho d z=\frac{1}{g} \int_{0}^{p_{s}} g z d p=\frac{1}{g} \int_{0}^{p_{s}} R T d p+z_{s} p_{s}
$$

after integrating by parts and using the hydrostatic approximation and equation of state, where $T$ is temperature, $R$ is the gas constant, and $z_{s}$ is the surface geopotential height. Hence $\tilde{I}+\tilde{P}=\mathrm{SH}+\Phi_{s}$, where the sensible heat $\mathrm{SH}=1 / g \int_{0}^{p_{s}} c_{p} T d p, c_{p}$ is the specific heat at constant pressure, and $\Phi_{s}=g z_{s}$ is the surface geopotential.

The thermodynamic equation can be written in advective form as

$$
c_{p}\left[\frac{\partial}{\partial t} T+\mathbf{v} \cdot \nabla T+\omega\left(\frac{\partial T}{\partial p}-\kappa \frac{T}{p}\right)\right]=Q_{1},
$$

where $Q_{1}$ the diabatic heating per unit mass includes frictional heating $\tilde{Q}_{f}$, and $\kappa=R / c_{p}$. The kinetic energy equation is

$$
\frac{\partial k}{\partial t}+\mathbf{v} \cdot \nabla k+\omega \frac{\partial k}{\partial p}=-\mathbf{v} \cdot \nabla g z+\mathbf{v} \cdot \mathbf{F},
$$

where $k=1 / 2\left(u^{2}+v^{2}\right)$ and $\mathbf{F}$ is friction. Variables $R, c_{p}$, and $\kappa$ all vary slightly with the amount of water vapor [see (4)], but can often be considered constant for our purposes. Adding these together gives the total dry energy equation

$$
\frac{\partial}{\partial t}\left(c_{p} T+k\right)+\mathbf{v} \cdot \nabla(s+k)+\omega \frac{\partial}{\partial p}(s+k)=Q_{1}-Q_{f},
$$

where $Q_{f}$ is the frictional heating arising from dissipation of kinetic energy, and $s=c_{p} T+g z$ is the dry static energy.

Owing to the need to deal with precipitation, it is often desirable to include a reference temperature so that the temperature in the sensible heat is not in Kelvin, but may be in degrees Celsius, for example. In that case, $s=$ $c_{p}\left(T-T_{0}\right)+g z$, and $T_{0}$ is also included in the tendency term; (15) is still valid, as both $T$ and $s$ are differentiated everywhere they appear. There may also be a term arising from the variability of $c_{p}$. The latter varies negligibly with temperature, but the variations with moisture are nontrivial. The term $c_{p} \approx c_{\mathrm{pd}}(1+0.85 q)$, where $c_{\mathrm{pd}}$ is the dry value. But the $q$ dependence can be taken 
care of using (6). Accordingly, there is no issue arising from including the reference temperature/sensible heat, and we now switch to this formulation.

To obtain the flux form of this equation, we add $(s+k)$ times (5) to give

$$
\begin{aligned}
\frac{\partial}{\partial t} & {\left[c_{p}\left(T-T_{0}\right)+k\right]+\nabla \cdot(s+k) \mathbf{v}+\frac{\partial}{\partial p}(s+k) \omega } \\
& =Q_{1}-Q_{f}+(s+k)(e-c)
\end{aligned}
$$

This is identical to Trenberth (1997) except for the reference temperature and the last term on the rhs involving the condensation and evaporation of moisture. It can be interpreted as the enthalpy arising from lack of local conservation of mass associated with precipitation. Note, however, that its magnitude depends greatly on the reference temperature.

Vertically integrating (16) gives

$$
\begin{aligned}
\frac{\partial}{\partial t} & \frac{1}{g} \int_{0}^{p_{s}}\left[c_{p}\left(T-T_{0}\right)+k+g z_{s}\right] d p+\nabla \cdot \frac{1}{g} \int_{0}^{p_{s}}(s+k) \mathbf{v} d p \\
& =\tilde{Q}_{1}-\tilde{Q}_{f}+(\tilde{s}+\tilde{k})(E-P)
\end{aligned}
$$

where lower boundary conditions are fully accounted for analytically (i.e., the variable surface pressure as part of the integral has been moved inside the mathematical operators and results in terms that cancel with the surface $\omega_{s}$ term). Here, the last term on the rhs of (16) has been broken up into the vertical mean and departures from the vertical mean, and the latter (involving covariability of the departures) is at least an order of magnitude smaller (see next section) and is ignored.

The moisture equation can readily be expressed in latent heat terms by multiplying (10) by $L$, the latent heat of vaporization:

$$
L \frac{\partial w}{\partial t}+\nabla \cdot \frac{1}{g} \int_{0}^{p_{s}} L q \mathbf{v} d p=-Q_{2}
$$

where the term $\tilde{Q}_{2}=L(P-E)$ is frequently referred to as the apparent latent heating arising from the apparent moisture sink [see Trenberth (1997) for more details]. Here we have ignored the variations in $L$, which depend linearly on temperature. The value of $L$ varies from 2.50 to $2.43 \times 10^{6} \mathrm{~J} \mathrm{~kg}^{-1}$ in going from 273 to $303 \mathrm{~K}$, a range of less than $3 \%$. Moreover, in (18), it is the horizontal gradients in $L$ and thus temperature that matter, and hence this is a very good approximation for our purpose. Combining (17) and (18) gives

$$
\begin{aligned}
\frac{\partial}{\partial t} & \frac{1}{g} \int_{0}^{p_{s}} A_{E} d p+\nabla \cdot \frac{1}{g} \int_{0}^{p_{s}}(h+k) \mathbf{v} d p \\
& =\tilde{Q}_{1}-\tilde{Q}_{f}-\tilde{Q}_{2}+(\tilde{s}+\tilde{k})(E-P),
\end{aligned}
$$

where $h=s+L q=c_{p}\left(T-T_{0}\right)+L q+\Phi$ is the moist static energy, and $A_{E}=c_{p}\left(T-T_{0}\right)+L q+k+\Phi_{s}$ is the total atmospheric energy.

For the vertical integrals, $\tilde{Q}_{1}$ is the sum of the downward net radiation at the TOA, the surface sensible and radiative heating, and the latent heating, plus any smallscale effects, and is the apparent diabatic heating. The use of "apparent" here is because it includes all of the small-scale unresolved eddy effects as well. The frictional heating $\tilde{Q}_{f}$ is very small and, as it is included in $\tilde{Q}_{1}, \quad \tilde{Q}_{1}-\tilde{Q}_{f}$ is the nonfrictional heating. Consequently, $\tilde{Q}_{1}-\tilde{Q}_{f}-\tilde{Q}_{2}$ is the sum of the TOA downward radiation plus the net upward surface fluxes, including the evaporative moistening flux LE. Therefore, it is also the net radiative flux convergence, plus the sensible heating and latent energy moistening. In terms of equations,

$$
\begin{aligned}
\tilde{Q}_{1}-\tilde{Q}_{f} & =R_{T}-R_{s}+\mathrm{SH}_{s}+\mathrm{LP}, \\
\tilde{Q}_{2} & =L(P-E), \\
\tilde{Q}_{1}-\tilde{Q}_{f}-\tilde{Q}_{2} & =R_{T}+F_{s}^{1}, \quad \text { and } \\
F_{s}^{1} & =\mathrm{LE}+\mathrm{SH}_{s}-R_{s},
\end{aligned}
$$

where $R_{T}$ is the TOA radiation downward, $R_{s}$ is the surface radiation, and both are made up of the solar and long-wave components, $\mathrm{SH}_{s}$ is the surface sensible heat, and $F_{s}^{1}$ is the conventional net surface flux upward. To this we must add the effective surface flux associated with the exchange of enthalpy arising from the transport of moisture,

$$
F_{s}^{2}=(\tilde{s}+\tilde{k})(E-P),
$$

so that the total surface flux is

$$
F_{s}=F_{s}^{1}+F_{s}^{2} .
$$

This means that (19) can be rewritten as

$$
\frac{\partial}{\partial t} \frac{1}{g} \int_{0}^{p_{s}} A_{E} d p+\nabla \cdot \frac{1}{g} \int_{0}^{p_{s}}(h+k) \mathbf{v} d p=R_{T}+F_{s},
$$

where $s=c_{p}\left(T-T_{0}\right)+\Phi, h=s+L q$, and $A_{E}=c_{p}(T-$ $\left.T_{0}\right)+L q+k+\Phi_{s}$, and for a steady state or even annual 
means where the tendency term is small, the balance lies between the atmospheric energy divergence, the net top-of-the-atmosphere radiation, and the surface fluxes. Within the ocean, again ignoring heat storage changes, the balance is between the vertically integrated ocean heat transport divergence and the net surface flux.

Given estimates of $R_{T}$ from satellite measurements and using computed values for terms on the left-hand side of (26), $F_{s}$ can be estimated as a residual. Over the oceans, this allows estimates to be made of the ocean heat transport, given the changes in ocean heat content. Moreover, $F_{s}$ can be compared with independent estimates made using bulk flux formulations of the surface fluxes.

Note that (26) is identical in form to that used in Trenberth (1997), Trenberth and Fasullo (2017), and many other earlier publications. The total surface flux, however, now includes the surface flux from enthalpy of precipitation, and hence the results would differ if one tried to compute the individual terms and sum them up. Note, however, that $Q_{1}$ [from (17)] and $Q_{1}-Q_{2}$ [from (19)] are different than before by the extra term, which is no longer allocated to the atmosphere but rather is part of the surface enthalpy.

\section{c. Mass correction procedures}

As noted above, and detailed in Trenberth $(1991,1997)$ and Trenberth et al. (1995, 2002b), there are many reasons why the atmospheric reanalyses do not conserve mass exactly, even if the underlying assimilating model does conserve mass. The main reasons relate to the unevenness of the observations over time, real high-frequency fluctuations, such as gravity waves, that are not captured in 6-h snapshot analyses, and analysis increments. Because the main term on the left in (26) involves the divergence of energy, it is extremely sensitive to spurious divergence, which can easily amount to terms of order several hundred $\mathrm{W} \mathrm{m}^{-2}$. Below, in the results section, we present the mass imbalance over time (Fig. 3) and how the various changes affect the outcomes (Figs. 4-7).

The main corrections employed in the past have been a barotropic adjustment to the velocity field (Trenberth 1991), and although three-dimensional adjustments are possible (Trenberth et al. 1995), they lose a lot in extra complexity and accuracy even as they gain in placing the adjustments in the right place. Nevertheless, as shown next, some improvements are possible by recognizing that it is at least desirable to take account of the fact that water is far more abundant in the lower troposphere, and water vapor plays a key role.

The first step in an adjustment is recommended to be this barotropic adjustment, but it should be performed without the $E-P$ term in (10) to deal with the dry air mass conservation (Trenberth 1991, 1997). Then a second step should be implemented to reinsert the true mass divergence associated with moisture transports, as given by (11). The rhs is already used to determine $E-P$ from (9), and it is clearly erroneous to distribute the convergence or divergence throughout the atmosphere in a barotropic manner when all of the action is heavily weighted by the $q$ distribution. Accordingly, all that is required from (11) is to take the core of the rhs, $\mathbf{v} q$, separate it into rotational and divergent components, $\mathbf{v} q=(\mathbf{v} q)_{r}+(\mathbf{v} q)_{d}$, and set the velocity correction $\mathbf{v}^{c}=(\mathbf{v} q)_{d}$. Then $\mathbf{v}=\mathbf{v}^{1}-\mathbf{v}^{c}$, where $\mathbf{v}^{1}$ is the velocity after the barotropic correction. This allocates the mass divergence or convergence according the moisture divergence. In this way, it also builds in any effects of evaporation from the surface of raindrops as they fall.

In practice, this last step turns out to be very difficult to implement, as it now requires all quantities to be computed as a function of pressure or on model levels, and we can no longer simply use only vertical integrals. Moreover, the required fields are not archived on model levels, notably geopotential height, for ERA-Interim (ERA-I) (but they are available for other new reanalyses). Accordingly, we have resorted to using the pressure-level archive for ERA-Interim. This means recomputing the moisture budget using only model levels and the mean monthly surface pressure to provide information on where the surface lies. This procedure brings in errors owing to coarser vertical resolution and the methods used to interpolate or extrapolate below ground. By comparing the pressure-level result with that from the full modellevel computation, we make some adjustments to the values in the lowest layer in order to reconcile the vertical integral, but it is inevitable that some noise and errors creep in. Nevertheless, the results show that this change is both necessary and desirable. In thefuture, this may be implemented in a better way, such as with other reanalyses (Bosilovich et al. 2017).

\section{The extra term, $F_{s}^{2}$}

As formulated here, we do not have a closed system because we have not (yet) included the ocean and the rest of the climate system. Moisture is evaporated from the surface and falls as precipitation elsewhere, and there has to be a return flow on land (as rivers) or in the ocean. Precipitation is an irreversible process and mass is lost to the atmosphere, but most of our treatment of the atmosphere assumes that processes are reversible. For example, the second law of thermodynamics assumes that entropy change is the ratio of heating to temperature for a reversible process, but entropy must increase for an irreversible process. When precipitation occurs, the water vapor condenses into liquid and leaves the atmosphere, but ends up at the surface or in the ocean. The loss of 


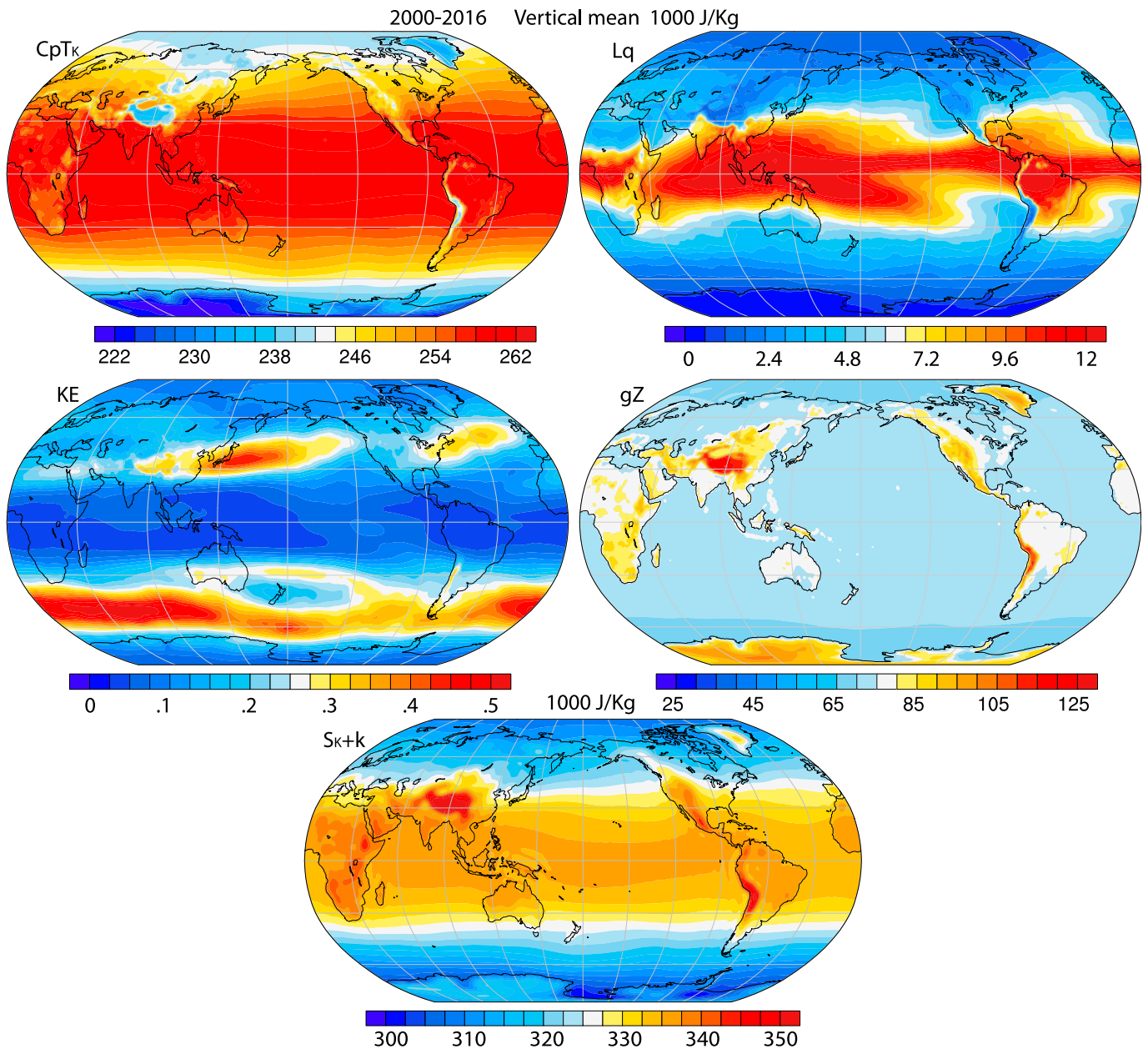

FIG. 1. Vertical means resulting from integrals for the year 2010 of (top 4 panels) $c_{p} T_{K}, L q, k$, and $g z$, and (bottom) $S_{K}+k$, in $1000 \mathrm{~J} \mathrm{~kg}^{-1}$. Here $T_{K}$ and $S_{K}$ make use of temperature in degrees $\mathrm{K}$.

atmospheric enthalpy is not related to the atmospheric and hence water vapor temperature, but rather the temperature difference between the atmosphere and the liquid at the surface, for which a more common reference value is $0{ }^{\circ} \mathrm{C}$ rather than $0 \mathrm{~K}$. This is where the formulation using a reference temperature becomes relevant.

The extra term we have included is $1 / g \int_{p_{s}}^{0}(s+k)(e-c) d p$. We can write $s=\left(g / p_{s}\right) \tilde{s}+s^{\prime}$, and so on, and the prime is the departure from the vertical mean, so that

$$
\frac{1}{g} \int_{\boldsymbol{p}_{s}}^{0}(s+k)(e-c) d p=(\tilde{s}+\tilde{k})(E-P)+\frac{1}{g} \int_{\boldsymbol{p}_{s}}^{0}\left(s^{\prime}+k^{\prime}\right)\left(e^{\prime}-c^{\prime}\right) d p
$$

and the other terms vanish. The evaporation above the surface is simply evaporation of precipitation drops, and so $e-c$ is really the net precipitation, with evaporation from elsewhere only coming in at the surface. The $k$ is very small. Consider first the absence of a reference temperature, and thus $s=c_{p} T+g z$. The terms that go into $\tilde{s}$ are given in Fig. 1 , and $\tilde{s}+\tilde{k}$ is also given. Note that $c_{p} d T+g d z=c_{p}\left(p / p_{00}\right)^{\kappa} d \theta$, so that fluctuations relate to those in potential temperature $\theta$. Typical values of $\tilde{s}$ are 310 to $340 \times 10^{3} \mathrm{~J} \mathrm{~kg}^{-1}$, and the first term in (27) is of order $15 \mathrm{~W} \mathrm{~m}^{-2}$. The second term in (27) is at least two orders of magnitude less. Accordingly, we are left with $F_{s}^{2}$ as given by (24).

There are a number of disconcerting aspects to the above formulation. In particular, results depend on the units used for temperature. It is conventional in atmospheric science to use Kelvin for temperatures. However, as noted above, we can include a reference temperature in the formulation. We choose $0^{\circ} \mathrm{C}$. Hence, we may compute $s$ using either temperature scale, and to be specific (Fig. 2) we use a subscript $\mathrm{K}$ or $\mathrm{C}$ to refer to the temperature scale used. 


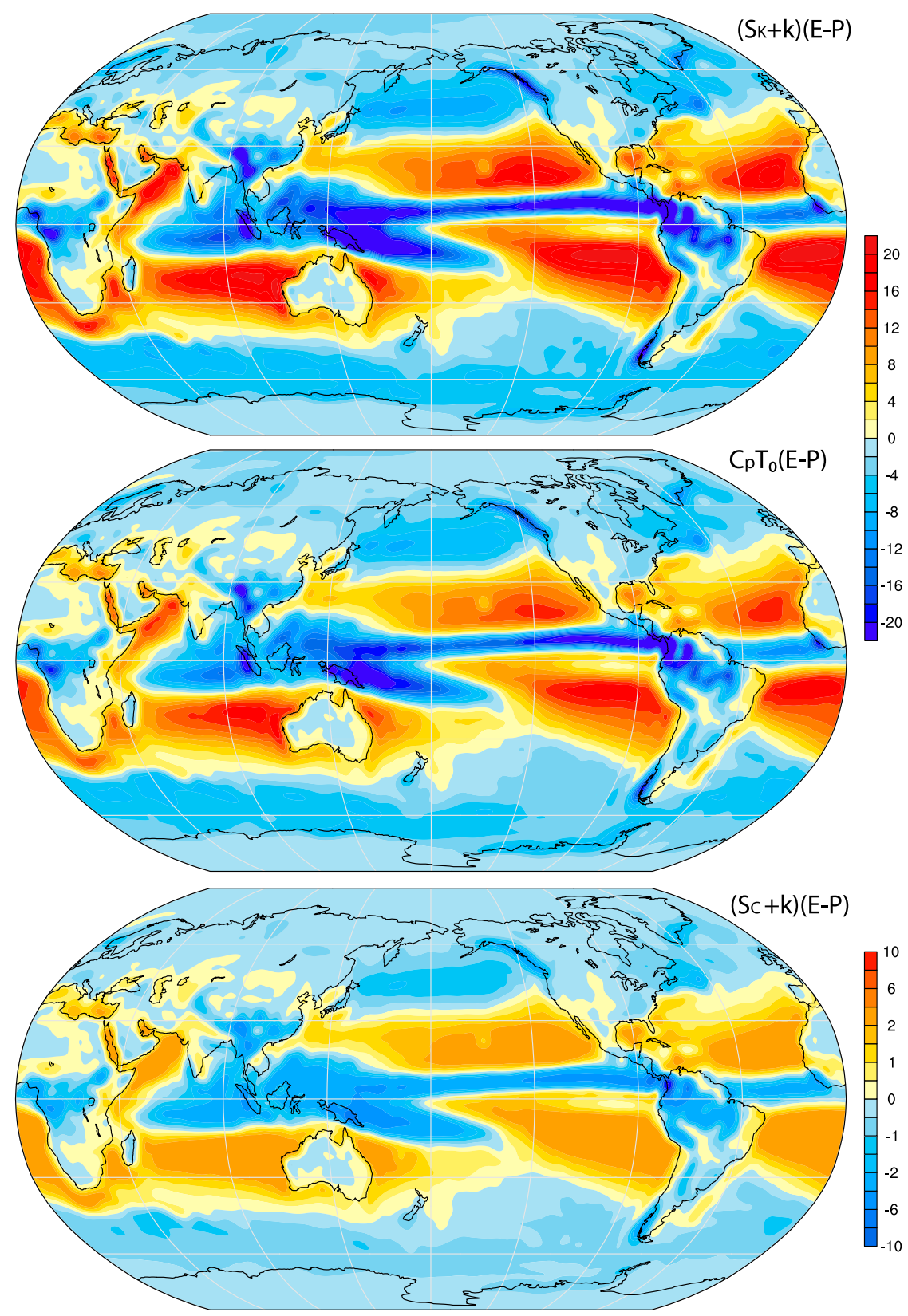

FIG. 2. (top) The full extra term $\left(S_{K}+k\right)(E-P)$ without the reference temperature; (middle) $c_{p} T_{0}(E-P)$, where $T_{0}=273.15 \mathrm{~K}$; (bottom) their difference (thus it is the extra term but with temperature in ${ }^{\circ} \mathrm{C}$, units $\mathrm{W} \mathrm{m}^{-2}$ ). The subscripts $\mathrm{K}$ and $\mathrm{C}$ refer to temperature computed in $\mathrm{K}$ or ${ }^{\circ} \mathrm{C}$.

In that case, $s_{C}=c_{p}\left(T-T_{0}\right)+g z$ is offset by an amount $273.15 c_{p}$ and the extra term on the rhs becomes a lot smaller. Indeed, $c_{p} T$ and $s$ in Fig. 1 are reduced by about $273000 \mathrm{~J} \mathrm{~kg}^{-1}$. The $s$ then ranges from about 35000 to $70000 \mathrm{~J} \mathrm{~kg}^{-1}$. For $E-P$ of $1 \mathrm{~mm} \mathrm{day}^{-1}$, the extra term $F_{s}^{2}$ would be reduced by $3.16 \mathrm{~W} \mathrm{~m}^{-2}$, or for $5 \mathrm{~mm}_{\text {day }}{ }^{-1}, 15.8 \mathrm{~W} \mathrm{~m}^{-2}$ (see Fig. 2). Hence the values of this extra term change from up to $\pm 25 \mathrm{~W} \mathrm{~m}^{-2}$ in Fig. 2 (top panel), to mostly much less than $\pm 4 \mathrm{~W} \mathrm{~m}^{-2}$ (see third panel, Fig. 2).

Of course, a comparable term is on the lhs of the equation, and so the extra part cancels. That is provided that it is included - and typically we have not included it consistently in the past (by ignoring it on the rhs). It also means that in the perturbation analysis, above, the perturbation terms are not quite so obviously negligible, 
although they are likely still an order of magnitude less, and much less than $0.5 \mathrm{~W} \mathrm{~m}^{-2}$. Also, this ambiguity potentially alters the interpretation of the extra terms.

By ignoring kinetic energy and interpreting $P$ as the net precipitation, the expression $F_{s}^{2}=(\tilde{s}+\tilde{k})(E-P) \approx-\tilde{s} P$. Now $s_{C}=c_{p}\left(T-T_{0}\right)+g z$ has to be vertically integrated, and we noted earlier that it is related to potential temperature. Hence, $F_{s}^{2}$ is very similar to the expression used earlier to estimate the enthalpy associated with precipitation $-c_{l} P\left(T_{p}-T_{0}\right)$, except that instead of the specific heat of liquid water, we have the enthalpy of the air where condensation occurred. Another factor is that we have also released LP latent heat. We note that $L=2.5 \times 10^{6} \mathrm{~J} \mathrm{~kg}^{-1}$, and $c_{l}=4186, c_{p}=1004, c_{l}-c_{p}=3182$, and $L / T_{0}=$ $9152 \mathrm{~J} \mathrm{~kg}^{-1} \mathrm{~K}^{-1}$, and this allows us to assess the magnitudes of the approximations. The geopotential term (Fig. 1) is equivalent to increasing $T$ by about 50 to $80 \mathrm{~K}(20 \%$ to $30 \%$ ). In our current equations, where there is no liquid water component, the enthalpy associated with precipitation emerges expressed in terms of the enthalpy of the air from whence the moisture condenses. It becomes an extra term in the flux form of the energy equations required to conserve energy, but it is not physically correct or complete. For example, as moisture is condensed, the volume decreases, and latent heat released raises the temperature. Because the latent heat of vaporization changes with temperature (since the boiling point of water increases with pressure), work may be done. Moreover, other neglected processes include friction of precipitation falling, exchange of heat and evaporation of drops with the environment, and so forth.

Romps (2008) has performed highly detailed calculations of the dry entropy budget of a moist atmosphere in a cloud-resolving model at high resolution and with all terms explicitly included, including liquid and ice phases of precipitation. For instance, he computes the effects from friction of rain falling ( 3 to $4 \mathrm{~W} \mathrm{~m}^{-2}$ ), and anemonal dissipation (viscous dissipation of eddies; 1.3 to $1.8 \mathrm{~W} \mathrm{~m}^{-2}$ ), while enthalpy of raindrops is similarly small $\left(<5 \mathrm{~W} \mathrm{~m}^{-2}\right.$ even for rain rates of $10 \mathrm{~mm} \mathrm{day}^{-1}$ and temperature differences of $10 \mathrm{~K}$ ). Several of these terms would be lumped into our $Q_{1}$ term.

Hence, in spite of the approximations and assumptions we have introduced, we have an energetically consistent formulation of (20) to (26) that can be used for diagnostic purposes. The differences from our previous diagnostics relate to $E-P$ and may be as large as given in Fig. 2. Accordingly, they do not play much of a role outside of the tropics and subtropics.

\section{Updated energetics of the atmosphere}

The atmospheric computations here all utilize only the European Centre for Medium-Range Weather
Forecasts (ECMWF) ERA-Interim reanalyses (Dee et al. 2011), as they are superior in several assessments and much improved over earlier reanalyses (e.g., Trenberth et al. 2011; Trenberth and Fasullo 2013), and CERES v4.0 TOA radiation (Loeb et al. 2009; see acknowledgments). We note that newer reanalyses are becoming available and offer extra fields that may have advantages. For instance, NASA Modern-Era Retrospective Analysis for Research and Applications, version 2 (MERRA-2), implemented a global mass adjustment to conserve mass (Takacs et al. 2016; Bosilovich et al. 2017), although this does not apply locally. However, preliminary evaluations suggest that MERRA-2 (Bosilovich et al. 2017) and JRA-55 (Kobayashi et al. 2015) still contain substantial biases (e.g., in top of atmosphere radiation) and inhomogeneities over time.

We present results for March 2000 (the beginning of the CERES record) through 2016 as annualized values using the new formulation, and we compare with updated results given by Trenberth and Fasullo (2017), which went through 2013. We further explore the differences resulting from the new formulation and the new mass correction.

\section{a. Mass correction}

The earlier studies discussed above documented the need for the huge mass corrections. More recent reanalyses have improved in this regard, and Fig. 3 provides the effects of the mass imbalance on the divergence of the total atmospheric energy $\nabla \cdot 1 / g \int_{0}^{p_{s}}(h+k) \mathbf{v} d p$. Here the changes are broken down by decade, and values exceed $\pm 120 \mathrm{~W} \mathrm{~m}^{-2}$ in the $1980 \mathrm{~s}$ and $1990 \mathrm{~s}$. Magnitudes of the correction are reduced in the 2000s, and by 2010 the values are mostly less than $60 \mathrm{~W} \mathrm{~m}^{-2}$. The patterns, however, are very similar throughout. We have also computed the annual cycle of the mass corrections (not shown), and they too have very similar patterns in each season. This indicates that the mass corrections are not tied to the atmospheric circulation itself or the diabatic heating patterns, but rather they relate to the observing system and the analysis procedures. The fact that there is a distinct wave- 4 pattern (Fig. 3) strongly suggests that the imbalance relates to the 4 times-per-day synoptic observations, and especially the twice-daily radiosonde soundings. The diminishing magnitudes over time suggest that improvements in the observing system were responsible, notably the transition from TIROS Operational Vertical Sounder (TOVS) to Advanced TOVS (ATOVS) completed in 2001, introduction of GPS radio occultation soundings in about 2002, which increased in volume in mid-2006, and Atmospheric Infrared Sounder (AIRS) soundings in late 2002. These corrections do not relate to the moisture 


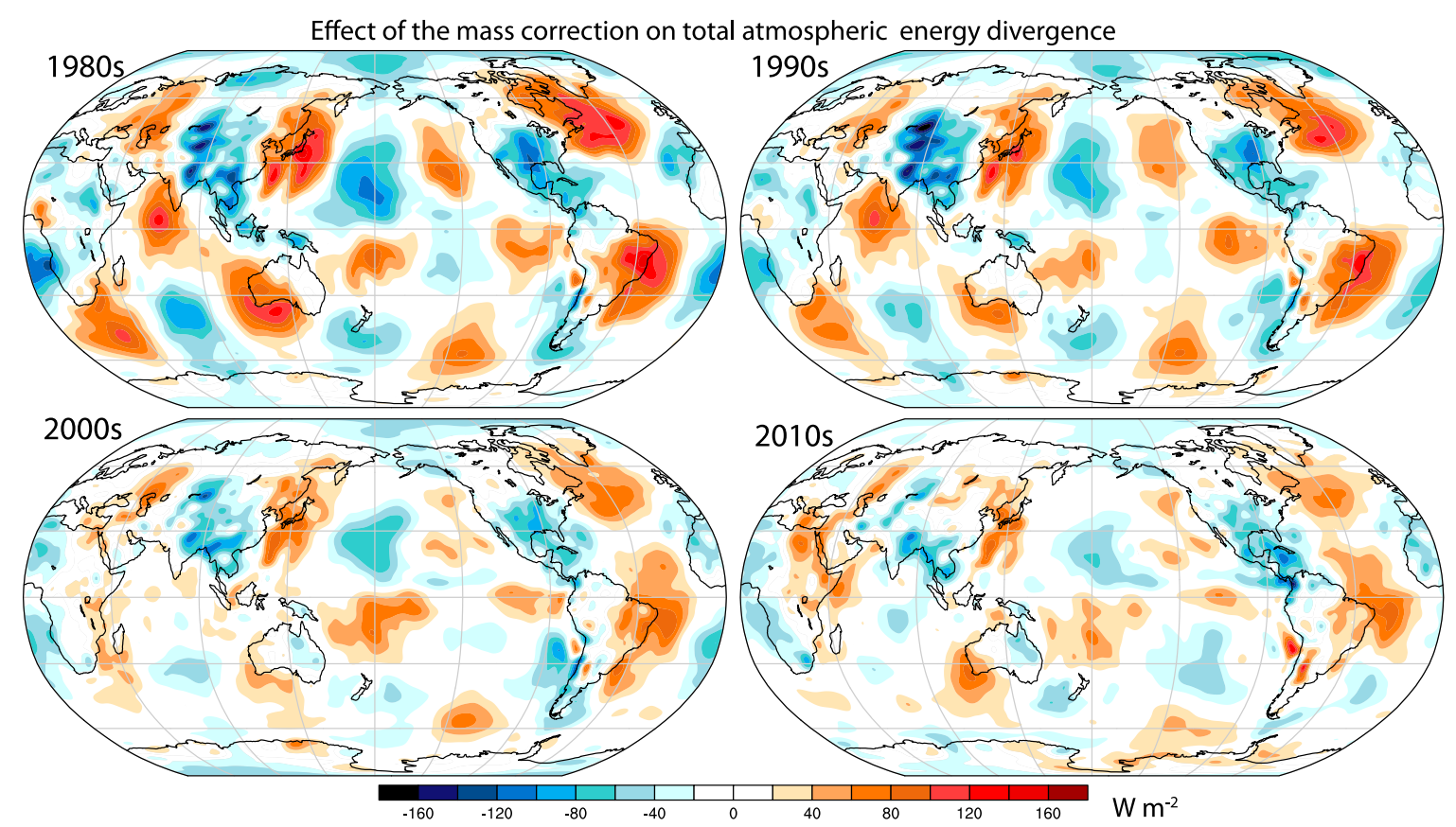

FIG. 3. The difference between making no mass correction vs with mass correction on the total atmospheric energy divergence $\nabla \cdot 1 / g \int_{0}^{p_{s}}(h+k) \mathbf{v} d p$ in $\mathrm{W} \mathrm{m}^{-2}$ for the 1980s, 1990s, 2000s, and 2010-16.

fields or $E-P$, but instead relate to the dry mass budget corrections.

\section{b. Energetics terms}

The new $Q_{1}-Q_{f}$ (Fig. 4) looks very much like the old one, because the values range from 250 to $-250 \mathrm{~W} \mathrm{~m}^{-2}$, while the differences are mostly less than $\pm 10 \mathrm{~W} \mathrm{~m}^{-2}$. The values are from (17), computed as a residual, and an extra term on the rhs of the equation related to $E-P$ plays a role. Effectively, if one computes $Q_{1}-Q_{f}$ without accounting for the extra term, the surface flux associated with precipitation becomes part of the atmospheric diabatic heating.

The $Q_{2}$ (Fig. 5) also looks very similar and the same reason applies: the differences of mostly less than $\pm 15 \mathrm{~W} \mathrm{~m}^{-2}$ are more than an order of magnitude less than the actual values. These differences arise entirely from the mass adjustment procedure, and highlight the fact that the original mass field is out of balance. In this case, we can evaluate the result by looking hard at the values over land, where we expect that the $P-E$ values should be positive because $P$ should exceed $E$ unless there is horizontal moisture transport by rivers and streams, or unless there is a lake involved. Hence, in the top two panels of Fig. 5 we see negative values over the Caspian Sea, and even the Great Lakes. But there are several places where the moisture budget is clearly incorrect, such as over parts of Australia, South America, and Africa (Trenberth and Fasullo 2013). In Australia, there is a residual to the water balance associated with too much evaporation in ERA-I (Trenberth et al. 2011; Albergel et al. 2012), so that mean values of $F_{S}$ over Australia are $-5 \mathrm{~W} \mathrm{~m}^{-2}$ (in both old and new). There are also errors in ERA-I precipitation, including over the central United States (Trenberth and Fasullo 2013).

Returning briefly to the $Q_{1}-Q_{f}$ differences (Fig. 4), the old method distributed the mass imbalance barotropically while the new method weights it appropriately with $q$. Given the further weighting by $(s+k)$ (see Figs. 1 and 2), the old method values tend to be higher because $(s+k)$ increases with height, leading to a difference that is a weighted version of $P-E$ and thus $Q_{2}$. There are several compensating changes that have occurred. As noted in Figs. 1 and 2, changing to degrees Celsius makes a difference, but including $E-P$ in the mass correction compensates somewhat, making the differences in Fig. 4 smaller than for Fig. 5.

The entire energy budget quantities for the atmosphere (Fig. 6) give $Q_{1}-Q_{f}-Q_{2}+F_{s}^{2}=R_{T}+F_{s}$ from [(19), (22), (24), and (26)]. Once again, the differences in the new versus old methods are relatively small, and they combine the differences of Figs. 4 and 5, but also add in the extra term $F_{s}^{2}$. The differences are very similar to but not identical to those in Fig. 4, mainly because of the differences between $s[(17)]$ and $h[(19)]$.

Given $R_{T}$ from CERES (v4.0), we can then compute the net surface energy flux $F_{s}$ as a residual from (25) (Fig. 7). In this case, the difference is identical to that in 

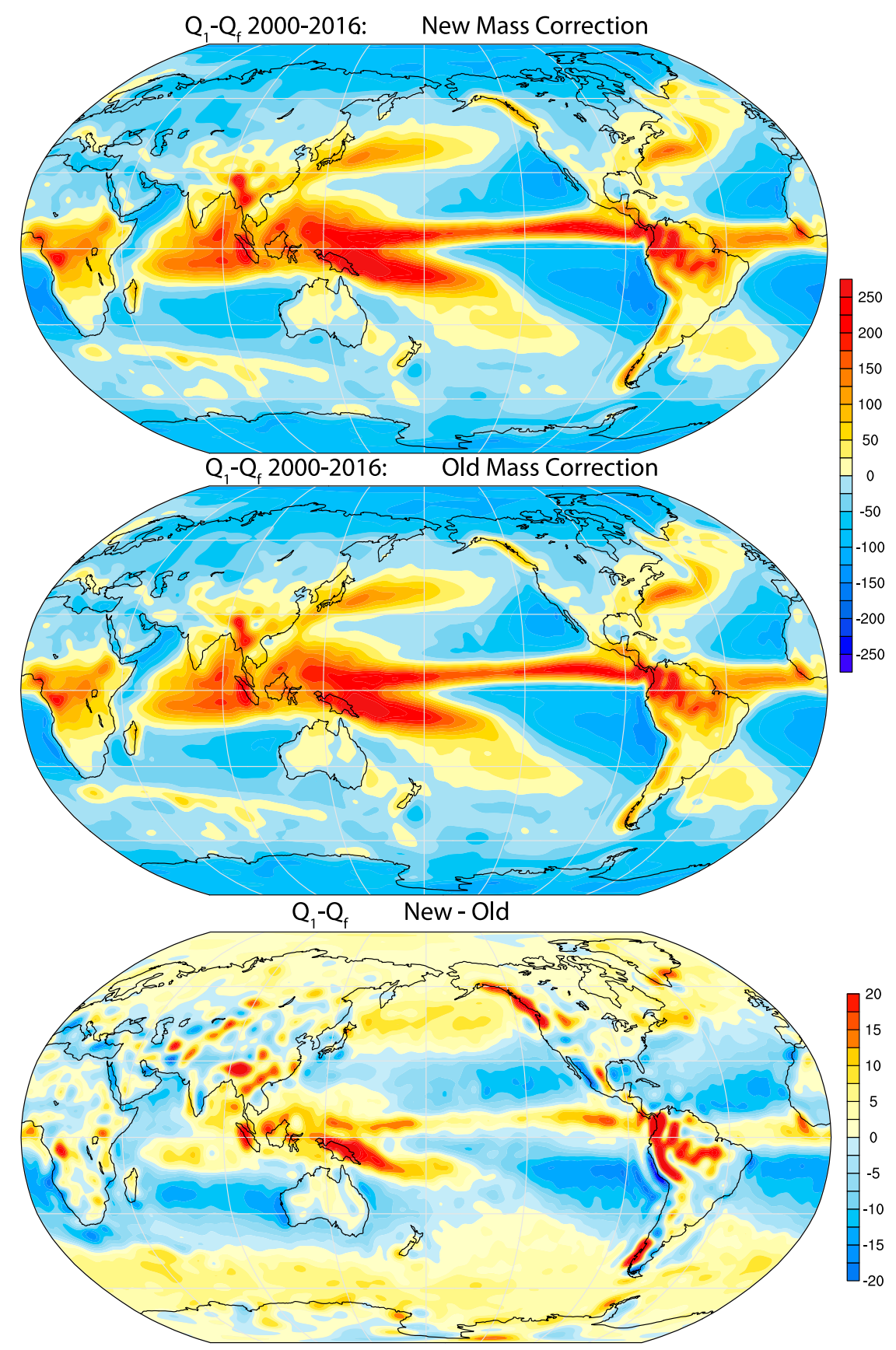

FIG. 4. The $Q_{1}-Q_{f}$ computed as a residual of (17) for annual means for March 2000 through 2016 in $\mathrm{W} \mathrm{m}^{-2}$. The result for the (top) entire new formulation is given vs (middle) the old formulation and (bottom) their difference.

Fig. 6. However, some small differences with the values of Trenberth and Fasullo (2017) arise from the new version of CERES (v4.0 instead of v2.8).

Now we can attempt an evaluation of the values over land where we expect values to be fairly small, as they are in both the old and the new computation. The differences (new vs old) are most pronounced near steep, high orography such as the Andes and Rockies, and partly stem from the change in $P-E$ (Fig. 5), and as a result, the rms values are almost identical for land as a whole: 13.1 and $13.3 \mathrm{~W} \mathrm{~m}^{-2}$ in the new versus old [compared with 16.9 and $18.0 \mathrm{~W} \mathrm{~m}^{-2}$ for Mayer et al. (2017); note that corrected values are given in their corrigendum]. Snow may be a small factor $\left(1\right.$ to $\left.2 \mathrm{~W} \mathrm{~m}^{-2}\right)$ 


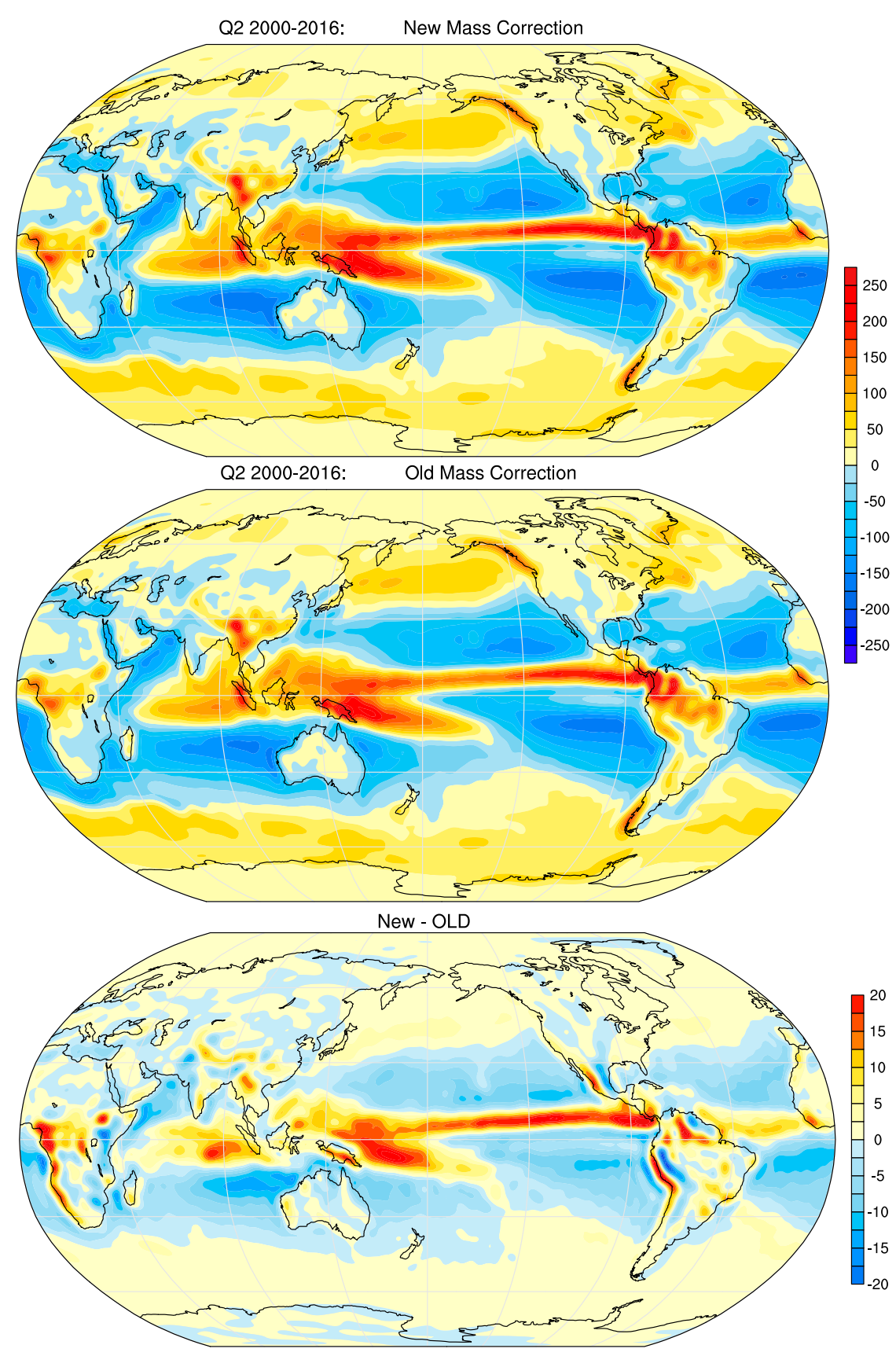

FIG. 5. The $Q_{2}=L(P-E)$ from (18) for annual means for March 2000 through 2016 in $\mathrm{W} \mathrm{m}^{-2}$. The result for the (top) entire new formulation is given vs (middle) the old formulation and (bottom) their difference.

over northern continents (Mayer et al. 2017). Large values in the Andes and African highlands and over Antarctica result in South America, Africa, and Antarctica having rms values over land of $16.9,14.8$, and $16.6 \mathrm{~W} \mathrm{~m}^{-2}$, respectively. As noted above, over Australia, the mean is $-5 \mathrm{~W} \mathrm{~m}^{-2}$ in both cases. The rms values are between 9 and $10 \mathrm{~W} \mathrm{~m}^{-2}$ for North America, and $11 \mathrm{~W} \mathrm{~m}^{-2}$ for Eurasia. Given the more complete evaluation by Trenberth and Fasullo (2013), it appears to be impossible to choose either the new or the old as better; both are quite good, with values less than $\pm 15 \mathrm{~W} \mathrm{~m}^{-2}$ in most places.

Over the oceans, the differences are more systematic. For instance, the new $F_{s}$ is higher by up to $5 \mathrm{~W} \mathrm{~m}^{-2}$ north of about $40^{\circ} \mathrm{N}$ and south of $50^{\circ} \mathrm{S}$, and lower by order $5 \mathrm{~W} \mathrm{~m}^{-2}$ in the subtropics (Fig. 7). We therefore repeat 


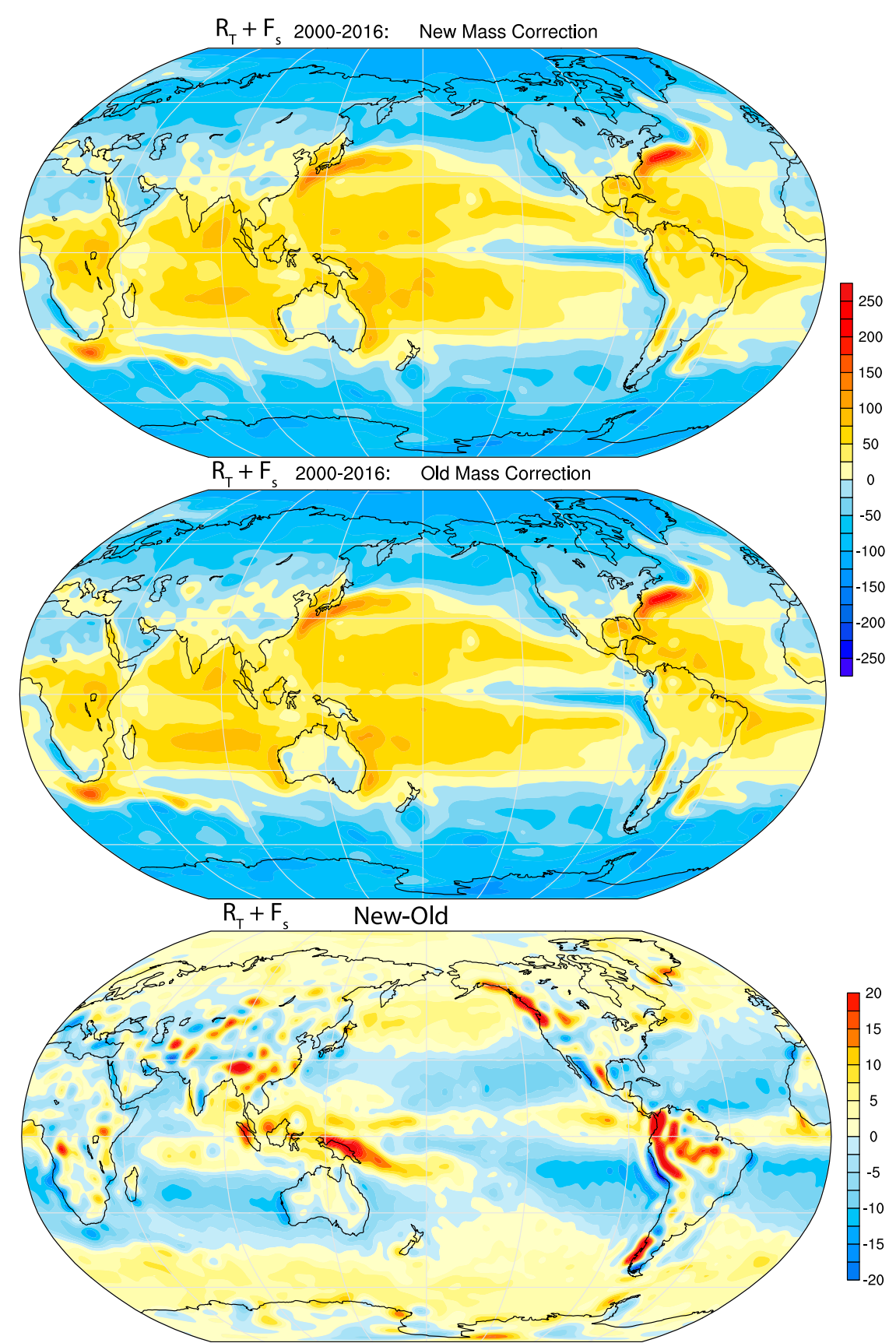

FIG. 6. The $Q_{1}-Q_{f}-Q_{2}+F_{s}^{2}=R_{T}+F_{s}$ from (19), (22), (24), and (26) for annual means

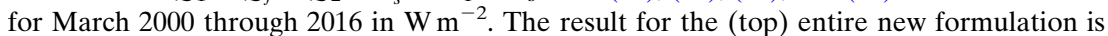
given vs (middle) the old formulation and (bottom) their difference.

the computation of the meridional heat transport in the Atlantic (Fig. 8), as in Trenberth and Fasullo (2017; their Fig. 4). The ocean surface heat flux is balanced by changes in $\mathrm{OHC}$ and transports of energy within the ocean and their divergence locally. As in Trenberth and Fasullo (2017), OHC is computed from the vertically integrated ocean reanalysis temperatures from ECMWF called the
Ocean Reanalysis Pilot 5 (ORAP5; Zuo et al. 2017), which goes only through 2013. Owing to the problem in ORAP5 OHC below $1000 \mathrm{~m}$ in the North Atlantic in a region off the Mediterranean Sea, we have only computed results using ORAP5 down to 1000-m depth. The values in Fig. 8 can be compared with Fig. 4 of Trenberth and Fasullo (2017), and although quite similar, 


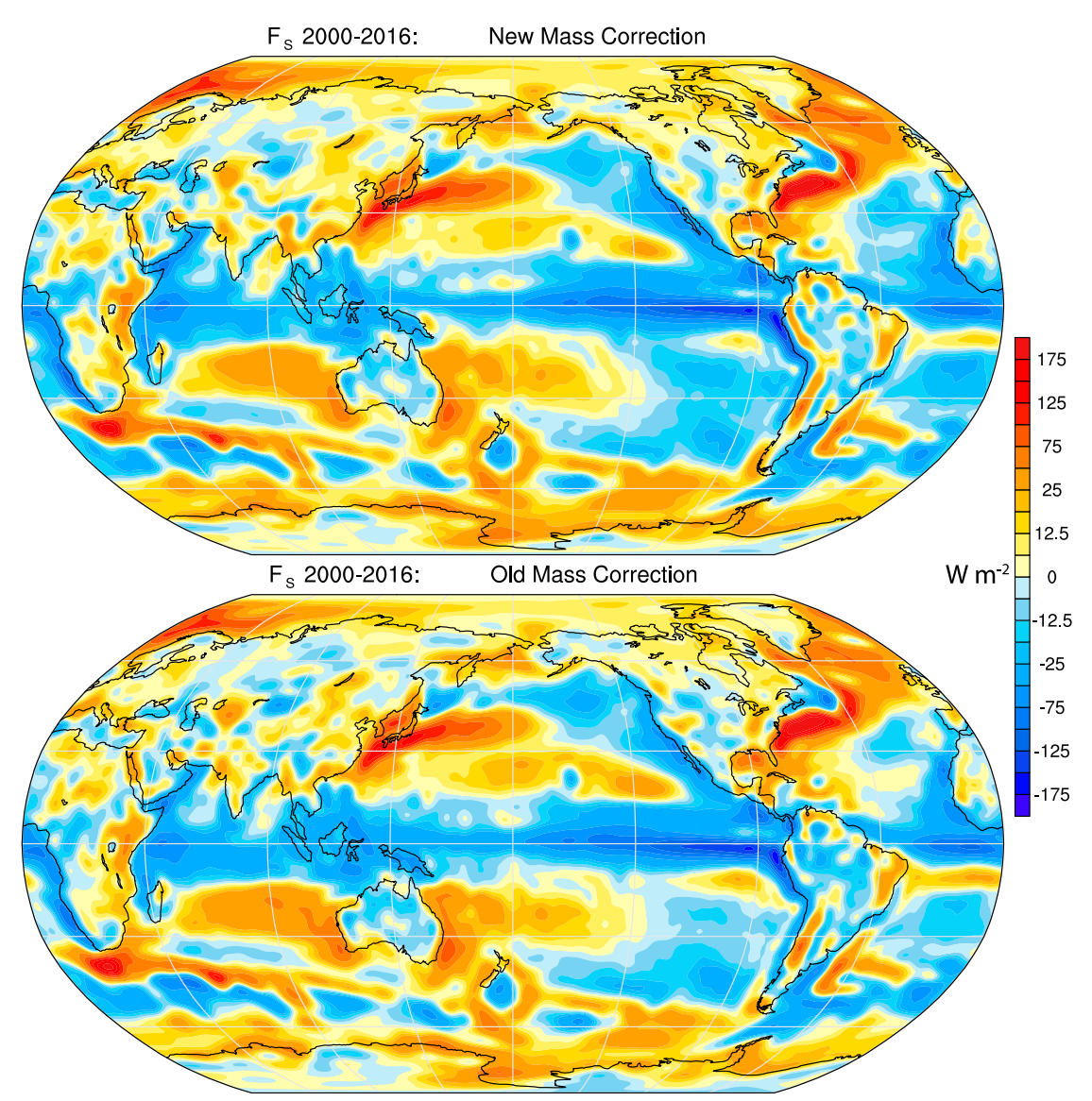

FIG. 7. The term $F_{s}$, the net surface heat flux, from (25) for annual means for March 2000 through 2016 in $\mathrm{W} \mathrm{m}^{-2}$. The result for the (top) entire new formulation is given vs (bottom) the old formulation. Their difference is the same as in Fig. 6.

differences are apparent. At $26^{\circ} \mathrm{N}$ where the comparison can be made with the results from the RAPID array (Fig. 9), the new values are slightly smaller around late 2003 to early 2004, late 2008 to mid-2009, and around 2011 by up to $0.04 \mathrm{PW}$, and larger by up to $0.04 \mathrm{PW}$ in 2002 and $0.01 \mathrm{PW}$ in late 2012/13.

\section{Discussion}

Recognition of shortcomings in the older formulation of energetic calculations was made by Mayer et al. (2017), who proposed an alternative formulation. However, their formulation is incomplete in some ways, more complete in others, and contains several invalid assumptions. The exploratory work we have done, as documented here, strongly suggests that the basic way the mass imbalance is adjusted is a key part of the problem and has issues attached to it that are comparable in size to the ones found by Mayer et al. (2017). Moreover, there are similar patterns because they all relate to $E-P$. In our new formulation, we recognize that there should be divergence of mass associated with $E-P$ and it has a vertical profile related to where precipitation forms. None of this is addressed in Mayer et al. (2017), who neglect the profile of where $P$ forms because they effectively assume that precipitation is a reversible process. Because we do not know where the net precipitation at the ground actually originates from, it led to a difficulty in implementing the approach we have adopted because we need all of the energy terms as a function of levels. While we have shown that the perturbations from the vertical mean can be neglected on average in the energy equation, we need the vertical profile of the variables for the mass adjustment. However, variables such as geopotential and geopotential height are not available from ECMWF on model levels. Although we need only monthly means, they too are not available. Accordingly, we had to use the pressure-level archive, which has substantial issues related to the lowest layer involving the surface.

It appears that Mayer et al. (2017) often deal with enthalpy, for example, of liquid water without properly 


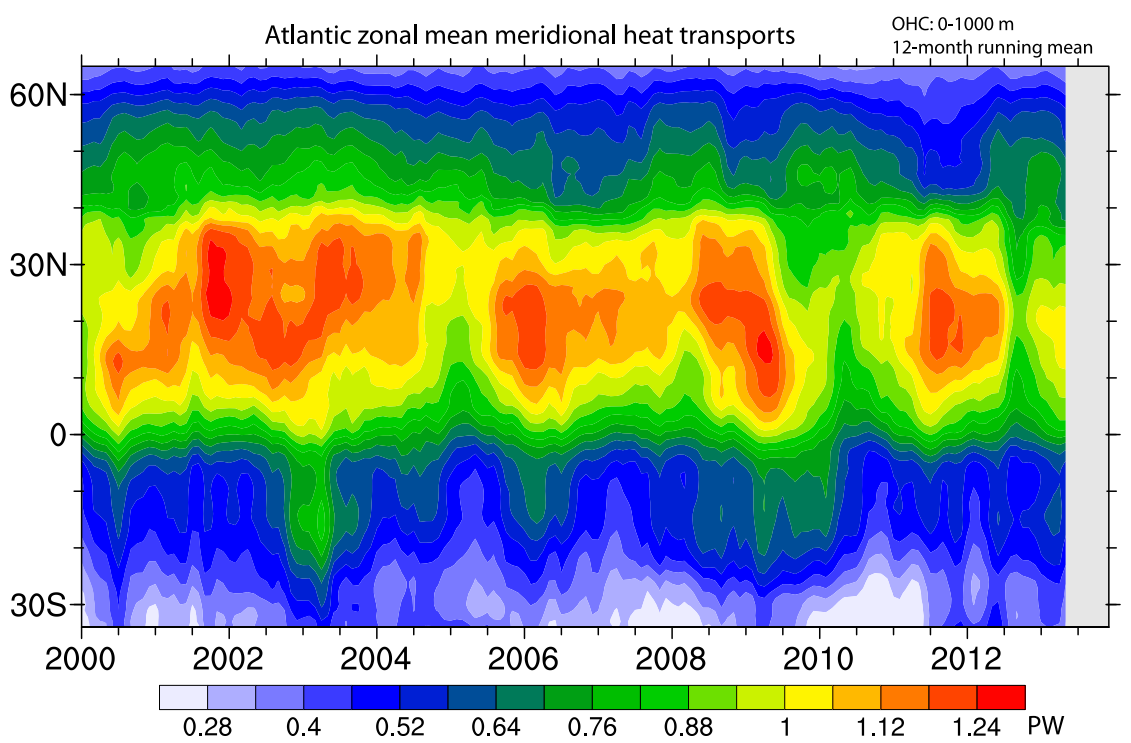

FIG. 8. Inferred zonal-mean meridional heat transport (PW) using the revised formulation with ERA-I data plus CERES 4.0 and ORAP5 OHC.

considering where the precipitation comes from in the atmosphere. They do not treat the variability of surface pressure in integrals [moving it from outside to inside a divergence operator-their Eq. (3)], and thus the surface vertical velocity is not treated correctly. Their equation of continuity (their appendix A) implicitly assumes that everything is reversible, and, although they treat liquid water explicitly (unlike our formulation), it is not rained out except right at the surface. Hence there is no precipitation arising from above the surface, and it only arises through the surface vertical motion in their formulation. One cannot make the vertical profile of $P$ vanish! Indeed, that is what provides the vertical profile of latent heat release and enthalpy from precipitation, and relates to the mass budget. As a result, in Mayer et al. (2017), subsequent developments of the flux form of the equations are missing part of a term (related to our extra term). Although they attempt a more complete formulation, for example by including snowfall aspects, there are other assumptions and approximations containing comparable errors. As a result, their final extra precipitation enthalpy term has only surface values rather than vertical integrals as ours does. Further, in dealing with snowfall, the issue is not total snowfall alone but rather whether the precipitation is frozen (i.e., the difference between rainfall and snowfall).

On the other hand, we have not discriminated between moist air with water vapor, and a liquid or solid component, as much as we perhaps should, and so there are approximations that lead to the sorts of discrepancies discussed in section 3 and how it relates to enthalpy of precipitation. The reason is that we have no information on these aspects from analyses and to go to this extra step creates other difficulties. The main resulting difference is that Mayer et al. (2017) include a specific heat of liquid water $c_{l}$ instead of $c_{p}$. However, it is important to emphasize that our formulation is consistent energetically because the same approximation is made on both sides of the equation in a term that cancels out. Accordingly, we believe that we have made some substantial advances in this paper, and the formulation is very useful and consistent for diagnostic work. Nevertheless, it involves

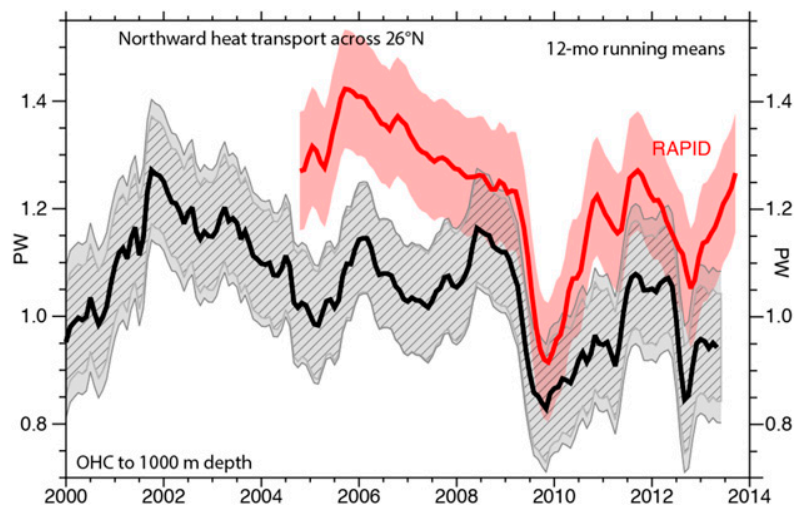

FIG. 9. RAPID array heat transports: The 12-month running mean northward heat transports across $26^{\circ} \mathrm{N}$ (black) from Fig. 8 compared with results from the RAPID array (red) in PW. The error bars are \pm 1 standard deviation, for RAPID in pink, and for current results in hatched gray, with a component (equivalent to a $0.42 \mathrm{~W} \mathrm{~m}^{-2}$ trend) added to represent trend uncertainty (plain gray). 
approximations by not including liquid or solid precipitation explicitly. Those challenges remain.

A key issue is how good are the results? A key place to check is over land, where the annual-mean energy budgets are constrained to be fairly small. The main variability arises from fluctuations in $E-P$ and storage of water on land, and there are small trends associated with warming land. However, the complexity of the land surface through both complex orography and heterogeneous vegetation creates both numerical and physical noise that can be significant locally, but which tends to average out over about $1000-\mathrm{km}$ scales. We have used the continental land regions as a key for evaluating the various reanalyses (e.g., Trenberth and Fasullo 2013), and found that ERA-Interim is the best available, although it clearly has shortcomings as discussed above. Our recent results (Trenberth and Fasullo 2017) using the old method were pretty good, as validated against ocean heat transports at $26.5^{\circ} \mathrm{N}$, and they are comparable to or better than the best results on land presented in Mayer et al. (2017). The new formulation, as given here, mainly features changes associated with $E-P$ and, accordingly, mainly in the tropics and subtropics. The differences are mostly less than $10 \mathrm{~W} \mathrm{~m}^{-2}$ except in the close proximity to steep orography, where our use of the pressure-level archive to perform the mass budget corrections likely introduces noise.

The changes also make only very small differences to the calculation performed in Trenberth and Fasullo (2017) of the inferred meridional heat transport in the Atlantic Ocean. At times, for several months, the integrated effects on the implied northward heat transports at $26^{\circ} \mathrm{N}$ are different by up to $0.05 \mathrm{PW}$, but mostly they are very small. The way we now compute the mass imbalance brings in corrections that cancel part of the corrections for the enthalpy of precipitation. Both the mass correction and the precipitation enthalpy adjustment need to go together.

The results of any energy budget analysis can only be as good as the input data or analyses. It is encouraging that the atmospheric reanalyses have improved sufficiently that the accuracies of less than $10 \mathrm{~W} \mathrm{~m}^{-2}$ matter, and accordingly, improved formulations of the basic equations are necessary. The advances made here suggest that the surface fluxes are reasonably well known to better than $\pm 10 \mathrm{~W} \mathrm{~m}^{-2}$ on about 1000 - $\mathrm{km}$ scalesexcept near steep orography, and much more accurately than can be achieved from the summing of all the bulk fluxes. Nevertheless, further improvements in atmospheric reanalyses, especially with respect to land evaporation and soil moisture (Albergel et al. 2012) and over oceans by relaxing specified SSTs, along with improvements in $\mathrm{OHC}$ estimates, should further narrow the closure issues in the future. Indeed, the main errors in our computations relate not to the formulation but rather to the input data. In addition, making available the mean fields at all levels on model levels and improving the mass imbalances in reanalyses, as is already happening (e.g., Takacs et al. 2016; Bosilovich et al. 2017), will clean up many of the issues in and near steep orography. The biggest errors in the ocean heat transports appear to arise from the $\mathrm{OHC}$ dataset used, and the evaluations suggest scope for substantial improvements there.

Acknowledgments. We thank Michael Mayer for discussions and suggestions and Michael Bosilovich for suggestions. This research is partially sponsored by DOE Grant DE-SC0012711. NCAR is sponsored by the National Science Foundation. We use monthly TOA Clouds and the Earth's Radiant Energy System (CERES) Energy Balanced and Filled (EBAF) Ed. 4.0 radiation (Loeb et al. 2009) from Langley Atmospheric Science Data Center (http://ceres.larc.nasa.gov/ order_data.php). The atmospheric data are the global reanalyses from ECMWF interim reanalysis (ERA-I; Dee et al. 2011; https://www.ecmwf.int/en/forecasts/datasets/ archive-datasets/reanalysis-datasets/era-interim). Data from RAPID-MOCHA are funded by the U.S. National Science Foundation and U.K. Natural Environment Research Council and were downloaded from https:// www.rsmas.miami.edu/users/mocha/mocha_results.htm.

\section{REFERENCES}

Albergel, C., P. de Rosnay, G. Balsamo, L. Isaksen, and J. MuñozSabater, 2012: Soil moisture analyses at ECMWF: Evaluation using global ground-based in situ observations. J. Hydrometeor., 13, 1442-1460, https://doi.org/10.1175/JHM-D-11-0107.1.

Bannon, P. R., 2002: Theoretical foundations for models of moist convection. J. Atmos. Sci., 59, 1967-1982, https://doi.org/ 10.1175/1520-0469(2002)059<1967:TFFMOM>2.0.CO;2.

Bosilovich, M. G., F. R. Robertson, L. Takacs, A. Molod, and D. Mocko, 2017: Atmospheric water balance and variability in the MERRA-2 reanalysis. J. Climate, 30, 1177-1198, https:// doi.org/10.1175/JCLI-D-16-0338.1.

Businger, J. A., 1982: The fluxes of specific enthalpy, sensible heat and latent heat near the earth's surface. J. Atmos. Sci., 39, 1889-1892, https://doi.org/10.1175/1520-0469(1982)039<1889: TFOSES $>2.0 . \mathrm{CO} ; 2$.

Cheng, L., K. E. Trenberth, J. Fasullo, T. Boyer, J. Abraham, and J. Zhu, 2017: Improved estimates of ocean heat content from 1960 to 2015. Sci. Adv., 3, e1601545, https://doi.org/10.1126/ sciadv. 1601545 .

Cotton, W. R., G. H. Bryan, and S. C. van den Heever, 2011: Fundamental equations governing cloud processes. Storm and Cloud Dynamics, 2nd ed. International Geophysics Series, Vol. 99, Academic Press, 15-52.

Dee, D. P., and Coauthors, 2011: The ERA-Interim reanalysis: Configuration and performance of the data assimilation system. 
Quart. J. Roy. Meteor. Soc., 137, 553-597, https://doi.org/ 10.1002/qj.828.

Emanuel, K. A., 1994: Atmospheric Convection. Oxford University Press, $580 \mathrm{pp}$

Fasullo, J. T., and K. E. Trenberth, 2008a: The annual cycle of the energy budget: Part I: Global mean and land-ocean exchanges. J. Climate, 21, 2297-2312, https://doi.org/10.1175/2007JCLI1935.1.

- and - 2008b: The annual cycle of the energy budget: Part II: Meridional structures and poleward transports. J. Climate, 21, 2313-2325, https://doi.org/10.1175/2007JCLI1936.1.

Gosnell, R., C. W. Fairall, and P. J. Webster, 1995: The sensible heat of rainfall in the tropical ocean. J. Geophys. Res., 100, 18 437-18 442, https://doi.org/10.1029/95JC01833.

IPCC, 2013: Climate Change 2013: The Physical Science Basis. T. F. Stocker et al., Eds., Cambridge University Press, 1535 pp.

Kobayashi, S., and Coauthors, 2015: The JRA-55 reanalysis: General specifications and basic characteristics. J. Meteor. Soc. Japan, 93, 5-48, https://doi.org/10.2151/jmsj.2015-001.

Loeb, N. G., B. A. Wielicki, D. R. Doelling, G. L. Smith, D. F. Keyes, S. Kato, N. Manalo-Smith, and T. Wong, 2009: Toward optimal closure of the earth's top-of-atmosphere radiation budget. J. Climate, 22, 748-766, https://doi.org/10.1175/2008JCLI2637.1.

Makarieva, A. M., V. G. Gorshkov, A. V. Nefiodov, D. Sheil, A. D. Nobre, P. Bunyard, P. Nobre, and B.-L. Li, 2017: The equations of motion for moist atmospheric air. J. Geophys. Res. Atmos., 122, 7300-7307, https://doi.org/10.1002/2017JD026773.

Mayer, M., and L. Haimberger, 2012: Poleward atmospheric energy transports and their variability as evaluated from ECMWF reanalysis data. J. Climate, 25, 734-752, https://doi.org/10.1175/ JCLI-D-11-00202.1.

$[,-$, and M. A. Balmaseda, 2014: On the energy exchange between tropical ocean basins related to ENSO. J. Climate, 27, 6393-6403, https://doi.org/10.1175/JCLI-D-14-00123.1.

—_ _ _ J. M. Edwards, and P. Hyder, 2017: Toward consistent diagnostics of the coupled atmosphere and ocean energy budgets. J. Climate, 30, 9225-9246, https://doi.org/ 10.1175/JCLI-D-17-0137.1; Corrigendum，31，2977-2978, https://doi.org/10.1175/JCLI-D-17-0855.1.

Ooyama, K. V., 2001: A dynamic and thermodynamic foundation for modeling the moist atmosphere with parameterized microphysics. J. Atmos. Sci., 58, 2073-2102, https://doi.org/ 10.1175/1520-0469(2001)058<2073:ADATFF $>2.0 . C O ; 2$

Romps, D. M., 2008: The dry-entropy budget of a moist atmosphere. J. Atmos. Sci., 65, 3779-3799, https://doi.org/10.1175/ 2008JAS2679.1.

Takacs, L. L., M. J. Suárez, and R. Todling, 2016: Maintaining atmospheric mass and water balance in reanalyses. Quart. J. Roy. Meteor. Soc., 142, 1565-1573, https://doi.org/10.1002/qj.2763.

Trenberth, K. E., 1991: Climate diagnostics from global analyses: Conservation of mass in ECMWF analyses. J. Climate, 4, 707-722, https://doi.org/10.1175/1520-0442(1991)004<0707: CDFGAC $>2.0 . \mathrm{CO} ; 2$.

__ 1997: Using atmospheric budgets as a constraint on surface fluxes. J. Climate, 10, 2796-2809, https://doi.org/10.1175/ 1520-0442(1997)010<2796:UABAAC $>2.0 . \mathrm{CO} ; 2$

— transports in the atmosphere and ocean. Climate Dyn., 10, 107-134, https://doi.org/10.1007/BF00210625.

, and J. M. Caron, 2001: Estimates of meridional atmosphere and ocean heat transports. J. Climate, 14, 3433-3443, https:// doi.org/10.1175/1520-0442(2001)014<3433:EOMAAO>2.0.CO;2.
— , and D. P. Stepaniak, 2003a: Covariability of components of poleward atmospheric energy transports on seasonal and interannual timescales. J. Climate, 16, 3691-3705, https://doi.org/ 10.1175/1520-0442(2003)016<3691:COCOPA > 2.0.CO;2.

, and —, 2003b: Seamless poleward atmospheric energy transports and implications for the Hadley circulation. J. Climate, 16, 3706-3722, https://doi.org/10.1175/1520-0442(2003)016<3706: SPAETA $>2.0 . \mathrm{CO} ; 2$.

, and J. T. Fasullo, 2008: An observational estimate of inferred ocean energy divergence. J. Phys. Oceanogr., 38, 984-999, https://doi.org/10.1175/2007JPO3833.1.

- and —, 2010: Tracking Earth's energy. Science, 328, 316317, https://doi.org/10.1126/science.1187272.

, and - 2013: Regional energy and water cycles: Transports from ocean to land. J. Climate, 26, 7837-7851, https://doi.org/ 10.1175/JCLI-D-13-00008.1.

- , and 2017: Atlantic meridional heat transports computed from balancing Earth's energy locally. Geophys. Res. Lett., 44, 1919-1927, https://doi.org/10.1002/2016GL072475.

- J. W. Hurrell, and A. Solomon, 1995: Conservation of mass in three dimensions in global analyses. J. Climate, 8, 692-708, https:// doi.org/10.1175/1520-0442(1995)008<0692:COMITD>2.0.CO;2.

_ J. M. Caron, and D. P. Stepaniak, 2001: The atmospheric energy budget and implications for surface fluxes and ocean heat transports. Climate Dyn., 17, 259-276, https://doi.org/ 10.1007/PL00007927.

,,--- , and S. Worley, 2002a: Evolution of El NiñoSouthern Oscillation and global atmospheric surface temperatures. J. Geophys. Res., 107, 4065, https://doi.org/10.1029/ 2000JD000298.

, D. P. Stepaniak, and J. M. Caron, 2002b: Accuracy of atmospheric energy budgets from analyses. J. Climate, 15, 3343-3360, https://doi.org/10.1175/1520-0442(2002)015<3343: AOAEBF $>2.0 . \mathrm{CO} ; 2$

, J. T. Fasullo, and J. Mackaro, 2011: Atmospheric moisture transports from ocean to land and global energy flows in reanalyses. J. Climate, 24, 4907-4924, https://doi.org/10.1175/ 2011JCLI4171.1.

—_ —_, and M. A. Balmaseda, 2014: Earth's energy imbalance. J. Climate, 27, 3129-3144, https://doi.org/10.1175/ JCLI-D-13-00294.1.

_ , Y. Zhang, J. T. Fasullo, and S. Taguchi, 2015a: Climate variability and relationships between top-of-atmosphere radiation and temperatures on Earth. J. Geophys. Res. Atmos., 120, 3642-3659, https://doi.org/10.1002/2014JD022887.

- — , and — $2015 \mathrm{~b}$ : Relationships among top-ofatmosphere radiation and atmospheric state variables in observations and CESM. J. Geophys. Res. Atmos., 120, 10 074-10 090, https://doi.org/10.1002/2015JD023381.

_ _ J. T. Fasullo, K. von Schuckmann, and L. Cheng, 2016: Insights into Earth's energy imbalance from multiple sources. J. Climate, 29, 7495-7505, https://doi.org/10.1175/ JCLI-D-16-0339.1.

von Schuckmann, K., and Coauthors, 2016: An imperative to monitor Earth's energy imbalance. Nat. Climate Change, 6, 138-144, https://doi.org/10.1038/nclimate2876.

Zuo, H., M. A. Balmaseda, and K. Mogensen, 2017: The new eddypermitting ORAP5 ocean reanalysis: Description, evaluation and uncertainties in climate signals. Climate Dyn., 49, 791-811, https://doi.org/10.1007/s00382-015-2675-1. 